\title{
The Role of Passion in Exercise Addiction, Exercise Volume, and Exercise Intensity in Long-term Exercisers
}

\author{
Rita Kovacsik $^{1}$ - Mark D. Griffiths ${ }^{2,3}$. \\ Halley M. Pontes ${ }^{2}$ - István Soós ${ }^{4} \cdot$ Ricardo de la Vega $^{5}$. \\ Roberto Ruíz-Barquín ${ }^{6}$ • Zsolt Demetrovics ${ }^{7}$ • \\ Attila Szabo ${ }^{7,8}$
}

Published online: 23 January 2018

C The Author(s) 2018. This article is an open access publication

\begin{abstract}
Recent studies have shown a relationship between the risk for exercise addiction (REA) and passion. This research examined whether levels of REA, volume of exercise (in weekly hours), and self-reported exercise intensities yield differences in obsessive passion and harmonious passion among individuals with long history of exercise. Respondents $(n=360)$ completed the Exercise Addiction Inventory, Passion Scale, and Borg Scale (assessing their usual exercise intensity), and reported their volume of exercise (hours per week). Regression analysis demonstrated that exercise intensity, obsessive passion, and harmonious passion were significant predictors $\left(r^{2}=.381, p<.001\right)$ of the REA scores with obsessive passion being the strongest predictor $\left(r^{2}=.318\right)$. Exercisers classified as at REA reported higher obsessive
\end{abstract}

Mark D. Griffiths

mark.griffiths@ntu.ac.uk

1 Doctoral School of Psychology, Faculty of Education and Psychology, ELTE Eötvös Loránd University, Budapest, Hungary

2 Psychology Department, Nottingham Trent University, Nottingham, UK

3 International Gaming Research Unit, Psychology Department, Nottingham Trent University, 50 Shakespeare Street, Nottingham NG1 4FQ, UK

4 Team of Sport and Exercise Sciences, Faculty of Health Sciences and Well-Being, University of Sunderland, Sunderland, UK

5 Department of Physical Education, Sport and Human Movement, Autonomous University of Madrid, Madrid, Spain

6 Department of Developmental and Educational Psychology, Autonomous University of Madrid, Madrid, Spain

7 Institute of Psychology, ELTE Eötvös Loránd University, Budapest, Hungary

8 Institute of Health Promotion and Sport Sciences, ELTE Eötvös Loránd University, Budapest, Hungary 
passion, harmonious passion, and exercise intensity $(p \leq .001)$ than those classified as symptomatic, who in turn scored higher on these measures $(p \leq .006)$ than asymptomatic exercisers. Participants reporting greater volumes of exercise also scored higher on obsessive passion, harmonious passion $(p<.001)$, exercise intensity $(p=.032)$, and REA scores $(p=.042)$ than individuals who exercised less. Finally, women exercising between low and high intensities exhibited greater obsessive passion, as well as harmonious passion $(p \leq .005)$ than men reporting similar exercise intensities. These findings support the recently reported relationship between passion and REA. They also expand the current knowledge by demonstrating that obsessive passion and harmonious passion are greater in the individuals who exercise at higher volumes and with higher intensities.

Keywords Compulsive exercise $\cdot$ Exercise dependence $\cdot$ Harmonious passion · Obsessive passion $\cdot$ Exercise addiction

Exercise addiction is a condition in which regularly exercising individuals lose control over their exercise behavior, as manifested by reoccurring compulsive urges to exercise and symptoms of dependence, resulting in negative consequences to their personal and/or social lives (Szabo et al. 2016). Exercise addiction has been classified as a behavioral addiction, similar to gambling disorder, but due to lack of empirical evidence for being a mental dysfunction, the condition is not listed in the latest (fifth) edition of the Diagnostic and Statistical Manual of Mental Disorders (American Psychiatric Association 2013). Indeed, to date, there are very few scholastic case reports on exercise addiction (Szabo et al. 2015), although a few have been published over the past two decades (e.g., Griffiths 1997; Hausenblas et al. 2017). Based on the interactional model (Egorov and Szabo 2013), case studies are essential given the lack of depth provided by other methodologies. Clinical case studies of exercise addiction provide detail about how the condition is triggered in affected individuals and provide insight into the etiology of the behavior in a way that is difficult via other methodologies. Additionally, actual or genuine cases of exercise addiction can only be identified via case studies, whereas survey data may be useful in the identifying of risk factors more generally. Despite the lack of in-depth case studies, the topic is popular among researchers as reflected by the numerous published works over the past decade (Szabo et al. 2015), which tend to assess the presumed risk for exercise addiction (REA) via responses on various scales for exercise addiction and dependence (Szabo et al. 2015). However, being classed at risk does not mean that the person is necessarily affected negatively by the condition (Schreiber and Hausenblas 2017).

The REA is often confounded with commitment to exercise (Szabo 2010) that involves passion for a beloved activity. Schreiber and Hausenblas (2017) admit that it is difficult to discern the fine line between passion and addiction, especially for the enthusiastic exercisers. However, there is a dual model for passion, reflecting harmonious and obsessive variants (Vallerand et al. 2003). Harmonious passion occurs when an activity is internalized autonomously and an individual flexibly engages in the activity, which is directly related to positive affect and it is inversely related to negative affect (Stenseng et al. 2011; Vallerand et al. 2003; Vallerand et al. 2006; Vallerand and Miquelon 2007). On the contrary, obsessive passion emerges when an individual internalizes the activity in a controlled way, when participation is rigidly controlled, and 
which is positively related to negative affect (Stenseng et al. 2011; Vallerand et al. 2003; Vallerand et al. 2007; Vallerand and Miquelon 2007). Additionally, obsessively passionate individuals attach great importance to activity contingencies, such as self-esteem and escape from problems (i.e., stress), which makes it difficult for them to stop the passionate activity (Vallerand 2010).

To date, few empirical studies have examined the relationship between REA and passion. Obsessive passion has been found to be positively associated with the REA in endurance sports as well as other leisure physical activities (Schipfer and Stoll 2015; Stenseng et al. 2011). It has been reported that that obsessive passion is associated with all the dimensions of the REA (i.e., time, reduction in other activities, tolerance, withdrawal, continuance, intention effects, and lack of control), which has not been established for harmonious passion which has only been found to relate to time and tolerance (Paradis et al. 2013). Moreover, it has been shown that harmoniously passionate exercisers can increase their exercise volume (i.e., frequency or duration) without jeopardizing essential life responsibilities. This does not appear to be the case for the obsessively passionate exercisers, who spend exaggerated amounts of time on exercise, while neglecting important responsibilities (Paradis et al. 2013). These findings are also supported by a Greek study showing that obsessive passion has a stronger association with REA scores than harmonious passion (Parastatidou et al. 2014), and a Swedish study demonstrating that those at high REA score higher on obsessive passion than those at low REA (Back 2015).

The relationship between the REA and passion, as a function of the athletic level of competition, was investigated in a recent study examining a large sample of low-level and high-level competitive athletes, and non-competitive leisure exercisers (De La Vega et al. 2016). In accord with Parastatidou et al. (2014), the findings demonstrated that obsessive passion was a relatively important predictor of the REA by accounting for $37 \%$ of the total variance in it. In contrast, harmonious passion was not a predictor of the REA. However, De La Vega et al. (2016) also reported that athletes scored higher on both obsessive and harmonious passion than leisure exercisers. Since exercise volume, in terms of the weekly hours of exercise, was greater in athletes than in leisure exercisers, the differences in passion may also be associated with exercise volume rather than athletic status. However, De La Vega et al. did not test this hypothesis.

Research has also demonstrated a stronger relationship of obsessive passion with total months of exercise (i.e., uninterrupted exercise experience) compared to harmonious passion (Parastatidou et al. 2012; Vallerand et al. 2003). Therefore, studying the association between REA and passion in long-term exercisers may provide a better understanding about the overlap between the two concepts. This rationale is expanded by Parastatidou et al.'s (2012) findings that both obsessive and harmonious passion are also positively related to the frequency of high-intensity exercise in addition to an individual's exercise history.

Given this background, the aims of the present study were to further investigate the association between the REA and passion in long-term exercisers (at least 2 years) as a function of the level of REA (low: asymptomatic, moderate: symptomatic, and high: at risk) as well as in categories of high and low exercise volume (using weekly hours of exercise), and high and low exercise intensities. Based on previous research showing the positive relationships between passion and exercise history, and passion and the REA, it was hypothesized that in long-term exercisers, the association between passion and REA would be even stronger than in previous research. It was also hypothesized that passion would be stronger in those individuals who exercise at higher intensity and in larger volumes. 


\section{Methods}

\section{Sample Size Calculation}

The minimum required sample size $(n)$ for linear multiple regression was calculated with the G*Power (v. 3) software (Faul et al. 2007). The a priori test as based on a pre-set power (1 $\beta=.95$ ), a medium effects size $\left(f^{2}=.15\right)$, and $\alpha=.05$, with four predictors (obsessive passion, harmonious passion, exercise volume, and exercise intensity), demonstrated that the required sample size was 129. Using the same software for calculating the sample size for betweengroups analyses based on a pre-set power $(1-\beta=.95)$, a medium effects size $\left(f^{2}=.25\right)$, and $\alpha=.05$, with four dependent measures, the required minimum sample size was 80 . Consequently, the current sample size ( $>300$ ) has exceeded the calculated minimum sample size.

\section{Participants}

Recruitment flyers and web adverts targeted the participants of a large city's fitness and recreational athletics clubs and solicited interested individuals to complete a 5-min online survey using Qualtrics software (Qualtrics 2017). Within a 3-month interval, 504 participants completed the survey of which 360 met the criteria for inclusion of being aged 18 years, being continuously physically active for at least 2 years, and exercising at least $3 \mathrm{~h}$ every week. Among the 144 respondents whose data were not included in the analyses, three were under 18 years of age, 16 did not supply the information regarding their exercise history, 76 were physically active for less than 2 years prior to the study, and 49 reported less than $3 \mathrm{~h}$ of regular exercise per week.

The final sample comprised 209 men (58\%) and 151 women (42\%). Participants' mean age was 24.37 ( $\mathrm{SD}=6.51$, range $18-78$ ) years, and they exercised an average of $6.99 \mathrm{~h}$ per week $(\mathrm{SD}=4.08$, range $3-30 \mathrm{~h})$, for an average of 8.95 years $(\mathrm{SD}=6.97$, range $2-40)$, and were involved in 32 different forms of exercise, which ranged from popular forms like running, swimming, and aerobics, to less common forms, such as kettleball (steel weights) use and pole dancing. Ethical clearance for the investigation was granted by ELTE Eötvös Loránd University's Ethics Committee in the Faculty of Education and Psychology.

\section{Materials}

A demographic questionnaire was used to determine the participants' gender, age, weekly hours of exercise, and past history of exercise. The 10-item Borg scale (Borg 1982) ranging from "very very light" (1) to "very very hard" (10) was used to assess the subjectively perceived usual or typical exercise intensity. The validated Hungarian version (Demetrovics and Kurimay, 2008) of the six item Exercise Addiction Inventory (EAI; Terry et al. 2004) was used to assess the risk for exercise addiction. Sample items include the following: "Exercise is the most important thing in my life." or "If I have to miss an exercise session I feel moody and irritable." EAI items are rated using a 5-point Likert scale, ranging from "strongly disagree" to "strongly agree," and has good psychometric properties (Griffiths et al. 2015; Monók et al. 2012; Terry et al. 2004). In the present sample, the internal reliability of the EAI (Cronbach's $\alpha$ ) was lower (.65) than in the original validation studies (i.e., 0.84; Griffiths et al. 2015; Terry et al. 2004) and only slightly lower than in the population-wide study of Monók et al. (2012; 0.72). However, given that previous studies most often assessed the internal consistency of the EAI in people 
taking part in one, or only a few forms of exercise, the lower values obtained in the current sample may be due to the very heterogeneous types of exercises (32 forms of exercise) in the present sample. However, the .65 value still falls within the range of internal consistencies reported for the EAI in several cross-cultural samples (i.e., .58 to .80; Griffiths et al. 2015).

Passion was assessed using the Hungarian version (Orosz et al. 2016) of the revised Passion Scale (PS; Marsh et al. 2013). Sample items include the following: "This activity is in harmony with the other activities in my life." or "If I could, I would only do my activity." The word "activity," in this case, refers to the form or forms of exercise engaged in. The scale assesses harmonious passion (HP) and obsessive passion (OP) across two 6-item subscales that are rated on a 7-point Likert scale, ranging from "not agree at all" to "very strongly agree". In the present study, the internal reliability of the OP and HP subscales (Cronbach's $\alpha$ ) were .77 and .79 , respectively, which are acceptable, but somewhat lower than the values reported by Marsh et al. for the original scale (i.e., .86 and .83 , respectively).

\section{Procedure}

Participants were able to take part in the study from anywhere by connecting to the Qualtrics platform, accessible via any computer or mobile phone connected to the Internet. The first page of the survey contained the informed consent form on which the participants had to click on an "agree" button before accessing the questions. Data collection lasted over a predetermined period of 3 months. The collected data were downloaded in SPSS (Statistical Package for Social Sciences, V.22) file format directly from the Qualtrics platform. After verifying the file for the completeness of the responses and the meeting of the criteria for participation, statistical analyses were performed with the same software.

\section{Statistical Analyses}

Spearman rank correlations were performed to establish the relationships between the studied variables. Subsequently, a multiple stepwise linear regression was used to identify the predictors (and their strength) of the REA scores. Low and high exercise volume groups, as well as exercise intensity groups, were created by using median splits. While dichotomization is criticized in the literature (Irwin and McClelland 2003), two recent re-evaluations, based on full simulation studies, have demonstrated that the practice is robust and reliable (Iacobucci et al. 2015a, 2015b). Given that no pre-selection was done for either exercise volume or exercise intensity, dichotomization was the only method to examine possible differences between the high-low categories of these variables. The REA group differences in the dependent measures were tested with group by gender multivariate analyses of variance (MANOVA).

\section{Results}

An initial correlation analysis yielded statistically significant positive associations between REA scores and all the dependent measures (see Table 1). Therefore, obsessive passion, harmonious passion, exercise intensity, and exercise volume were presumed the predictors of REA scores which were tested with a stepwise regression analysis. Since all correlations were under 0.70 , none of the predictors were multicollinear. Because there was no statistically 
Table 1 Spearman's rho $(\rho)$ inter-correlations between the measures

\begin{tabular}{lllll}
\hline & $\begin{array}{l}\text { Obsessive } \\
\text { passion }\end{array}$ & $\begin{array}{l}\text { Harmonious } \\
\text { passion }\end{array}$ & $\begin{array}{l}\text { Exercise } \\
\text { volume }\end{array}$ & $\begin{array}{l}\text { Exercise } \\
\text { intensity }\end{array}$ \\
\hline $\begin{array}{l}\text { Risk for exercise addiction } \\
\quad \text { REA) }\end{array}$ & $.543(p<.001)$ & $.454(p<.001)$ & $.129(p=.014)$ & $.332(p<.001)$ \\
$\begin{array}{l}\text { Obsessive passion } \\
\text { Harmonious passion }\end{array}$ & & $.636(p<.001)$ & $.272(p<.001)$ & $.352(p<.001)$ \\
Weekly hours of exercise & & & $.331(p<.001)$ & $.330(p<.001)$ \\
\hline
\end{tabular}

significant correlation between REA scores and exercise volume, the latter was not included in the regression analysis. First, an analysis of the standard residuals was carried out to identify possible outliers in the data. This test indicated that one participant needed to be removed. After removing this outlier, the re-test of the standardized residuals indicated that the data did not contain any further outliers (St. Rsd. Min. $=-2.669$, St. Rsd. Max. $=2.889$ ). The data met the assumption of independent errors (Durbin-Watson value $=1.807$ ) and the assumption of non-zero variances (harmonious passion, variance $\left(s^{2}\right)=27.27$, obsessive passion, $s^{2}=41.85$, and exercise intensity, $\left.s^{2}=1.75\right)$. Using the stepwise method, a statistically significant regression equation was obtained where all the three predictors were components of the model $(F[3$, $355]=72.745, p<.001, R^{2}=.381, R^{2}$ adjusted $=.375$; Table 2$)$. The proportion of variance $\left(R^{2}\right.$ change) explained in the REA scores by obsessive passion was the largest (.318), less by exercise intensity (.045), and only minimal (.018) by harmonious passion.

To test the differences between the REA groups (as based on Terry et al. 2004), (i) at risk (scores 24 or above; $n=15^{1}$ ), (ii) symptomatic (scores between 13 and $23 ; n=281$ ), and (iii) asymptomatic (scores between 6 and 12;n=64), a three (REA groups) by four (measures: obsessive passion, harmonious passion, exercise intensity, and exercise volume) MANOVA was performed. The test yielded a statistically significant multivariate main effect for the three REA groups (Pillai's Trace $=.231, F(8,708)=11.54, p<.001$, partial ETA squared $\left(\eta_{p}{ }^{2}\right)=.115$ ). Univariate tests revealed that the REA groups differed from each other on three out of four dependent measures: (i) obsessive passion $\left(F(2,356)=34.16, p<.001, \eta_{p}{ }^{2}=.161\right)$; (ii) harmonious passion $\left(F(2,356)=25.13, p<.001, \eta_{p}{ }^{2}=.124\right)$; (iii) exercise intensity $(F(2,356)=25.19$, $\left.p<.001, \eta_{p}{ }^{2}=.124\right)$. Bonferroni corrected post hoc tests showed that the groups differed from each other in all the three dependent measures ( $p \leq .006$; see Fig. 1). The prevalence of REA in the current sample was $4.17 \%$ (15 of 360 individuals).

To examine whether people who exercise more show greater passion and REA than those who are exercising less, median ( $6 \mathrm{~h}$ per week) split-based high and low exercise volume groups were formed. The dichotomization was deemed to yield robust and reliable findings because multicollinearity was not present in the data (VIF 1.0-1.7 that is <3; Iacobucci et al. 2015a, $2015 b)$. The two emerging groups were compared on obsessive passion, harmonious passion, exercise intensity, and REA scores using a two (group) by two (gender) by four (dependent measures) MANOVA. The test yielded a statistically significant multivariate main effect for the groups only (Pillai's Trace $=.083, F(4,356)=8.03, p<.001, \eta_{p}{ }^{2}=.083$ ). The univariate tests showed that statistically, the high and low exercise volume groups differed significantly from each other on all the four measures $(p<.001$; see Table 3$)$.

\footnotetext{
${ }^{1}$ Since this group was comprised by nine men and six women, there was insufficient power to include gender in the analysis.
} 
Table 2 Summary of the results of the stepwise regression analysis where risk for exercise addiction (REA) is the dependent variable and obsessive passion, harmonious passion, and exercise intensity are predictor variables $(n=359)$

\begin{tabular}{llllllll}
\hline Predictor & $\beta^{*}$ & $S E^{* *}$ & $t$ & $p$ & $\begin{array}{l}\text { 95\% confidence } \\
\text { interval for } \beta\end{array}$ & Tolerance \\
\hline Obsessive passion & .241 & .035 & 6.88 & $<.001$ & .172 & .310 & .570 \\
Exercise intensity & .063 & .014 & 4.48 & $<.001$ & .035 & .090 & .855 \\
Harmonious passion & .138 & .043 & 3.18 & $=.002$ & .053 & .223 & .569 \\
\hline
\end{tabular}

$\beta^{*}$ unstandardized coefficients, $\mathrm{SE}^{* *}$ standard error of $\beta$

An identical dichotomization-based grouping was performed for exercise intensity (median $=8.1$ on Borg scale) and a 2 (group) by 2 (gender) by 4 (dependent measures: obsessive passion, harmonious passion, exercise volume, and REA scores) MANOVA was calculated. Since this test yielded a multivariate group by gender interaction (Pillai's Trace $=.032, F(4,330)=2.69, p=.031, \eta_{p}{ }^{2}=.032$ ), the main effects were not considered further. Univariate tests showed that the interaction was statistically significant only for obsessive passion $\left(F(1,333)=6.67, p=.010, \eta_{p}{ }^{2}=\right.$ $.020)$ and harmonious passion $\left(F(1,333)=7.47, p=.007, \eta_{p}^{2}=.022\right)$. The interaction was due to the fact that women exercising at lower intensities (Borg scale 1-7) reported greater obsessive passion $(F(1,162)=9.10, p=.003)$ and harmonious passion $(F(1,162)=8.07, p=.005)$ than men exercising at the same intensities. As Fig. 2 demonstrates, there were no such gender differences in those exercising at very high exercise intensities.

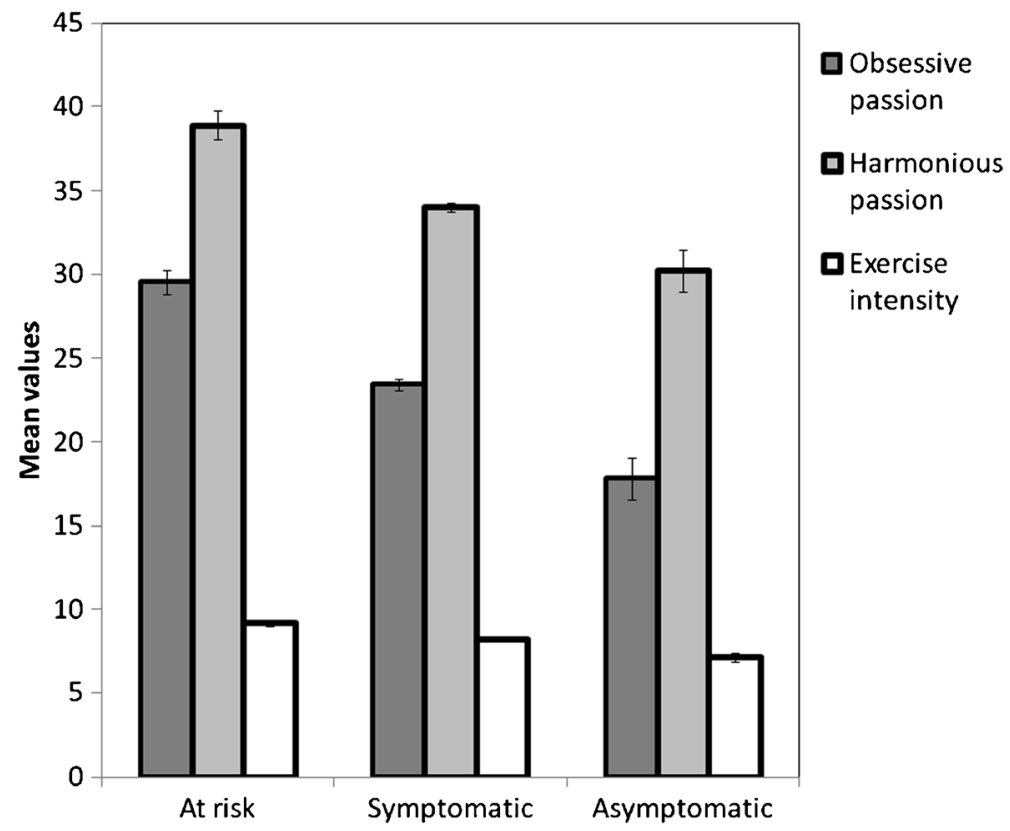

Fig. 1 Bonferroni corrected post hoc tests showing the difference of the groups in all the three dependent measures 
Table 3 Means $(M)$, standard deviations (SD), and statistically significant differences between high $(n=202)$ and low $(n=158)$ exercise volume groups in four dependent measures $(\mathrm{df}=1,356)$

\begin{tabular}{lllllll}
\hline Dependent measure & $\begin{array}{l}\text { High exercise } \\
\text { volume }(M \pm \mathrm{SD})\end{array}$ & $\begin{array}{l}\text { Low exercise } \\
\text { volume }(M \pm \mathrm{SD})\end{array}$ & $F$ & $p$ & $\eta_{p}{ }^{2}$ & Power $(1-\beta)$ \\
\hline Obsessive passion & $24.15(6.10)$ & $20.84(6.46)$ & 16.98 & $<.001$ & .046 & .984 \\
Harmonious passion & $35.02(4.31)$ & $31.72(5.68)$ & 29.9 & $<.001$ & .078 & 1.000 \\
Exercise intensity & $8.22(1.21)$ & $7.77(1.42)$ & 4.62 & $=.032$ & .013 & .572 \\
Risk for exercise addiction (REA) & $16.94(4.09)$ & $15.78(4.09)$ & 4.15 & $=.042$ & .012 & .528 \\
\hline
\end{tabular}

\section{Discussion}

The results of the study confirm and strengthen previous studies associating exercise addiction with obsessive passion (Paradis et al. 2013; Schipfer and Stoll 2015; Stenseng et al. 2011). It also affirms the findings of De La Vega et al. (2016) and Parastatidou et al. (2014) showing that obsessive passion manifests a stronger relationship with exercise addiction than harmonious passion. In accord with the findings of the De La Vega et al. (2016), the present study demonstrated that obsessive passion was the strongest predictor of the REA scores explaining nearly $32 \%$ of variance (similar to the $39 \%$ variance found by De La Vega et al. [2016]). The small difference may be attributed to differences in the examined samples, such as athletes at two levels of competition versus leisure exercisers and the associated sporting context. While the study by De La Vega et al. (2016) found that harmonious passion was not a predictor of the REA scores, in the present study, it emerged as a statistically significant predictor. However, this was a weak (and arguably negligible) predictor because it accounted for less than $2 \%$ of the variance in the REA scores. This finding is not surprising if one considers that harmonious passion mirrors the joyful (subjective) experience in which exercise is perceived as a form of life enriching activity in harmony with other significant life affirming activities (Vallerand et al. 2003; Vallerand 2010).

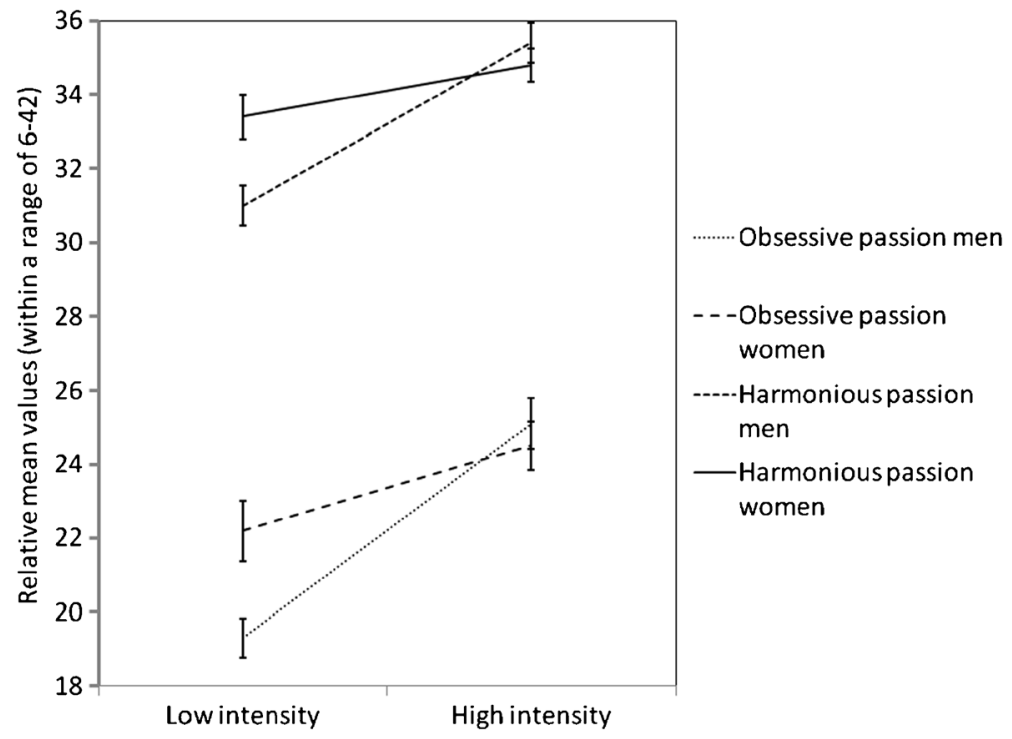

Fig. 2 Difference in those exercising in low and high intensities 
The prevalence of REA was $4.2 \%$ in the present study which is similar to the values reported for leisure exercisers elsewhere in the literature ranging from 1.9 to $3.2 \%$ (Szabo et al. 2015). However, it is lower than that reported for athletic populations ranging between 17.0 and 41.4\% (Blaydon and Lindner 2002; Costa et al. 2015; McNamara and McCabe 2012). Indeed, such "exaggerated" prevalence rates prompted Szabo et al. (2015) to question the interpretation of the EAI items by elite athletes who score unusually high on this tool and may simply reflect their passion for exercise rather than addiction. This conjecture is also supported by the present findings demonstrating that long-term, higher volume, and higher intensity exercisers report greater obsessive and harmonious passion than those who exercise less hours at lower intensities. These results echo the findings from previous research, showing that long-term and highintensity exercise are related to both forms of passion (Parastatidou et al. 2012; Vallerand et al. 2003).

A novel and unexpected finding was that women reported greater passion if they exercised under the median value of the reported range of exercise intensities than men working out at the same effort. However, the differences were no longer noticeable above the median, at the very high exercise intensities (see Fig. 2). These findings are in discord with reports in the literature, which show no gender differences in passion (Philippe et al. 2009; Vallerand et al. 2008). There is no obvious reason why such a difference was found in the present study and further research will be needed to establish whether the findings here are unrepresentative of studies in general or there really is a gender difference.

The finding that obsessive passion and harmonious passion increase with the levels of REA classifications (Terry et al. 2004) shows that apart from a mere correlation between passion and the REA scores (which emerges more strongly for obsessive than harmonious passion), passion scores paralleled those of REA scores. Along with perceived exercise intensity, harmonious passion is as much involved in this relationship as is obsessive passion. Indeed examination of Fig. 1 shows a parallel increase with the levels of REA scores. This finding may suggest that what today is conceptualized as "risk" for exercise addiction may be a complex and yet untangled hybrid of exercise parameters and passion. Therefore, the current findings-supporting and expanding the few recent research results - call for the differentiation of REA from passion while the moderators of the relationship between the two are also identified. Such work in the field is necessary, because the difference in the reported exaggerated prevalence rates in competitive/elite athletes, ranging between 17.0 and $41.4 \%$ (Blaydon and Lindner 2002; Costa et al. 2015; McNamara and McCabe 2012) in contrast to the rates of REA in the general population $(0.5 \%)$ as based on the only population-wide representative study (Monók et al. 2012), shows that there is a conceptual confound in the field of exercise addiction. Knowing about the involvement of passion in REA, mediating role of exercise volumes and intensity will help facilitate future systematic research aimed at conceptual clarification of REA.

\section{Limitations}

The present study is not without limitations. One obvious limitation is the lack of random sampling. Volunteers are unlikely to come from the same population as those in a random sample. Another limitation is the low sample size in the at-risk REA group, which prevented gender group analysis in this sub-group. However, based on 
past literature (Szabo et al. 2015), this prevalence rate was expected. A further limitation may be the use of self-report data (which are subject to social desirability bias) and the retrospective assessment of both exercise volume and intensity (which are subject to recall bias). Most individuals may easily be able to calculate their average weekly exercise but the perceived intensity may often be more important in terms of subjective expectations and outcomes than the actual exercise intensity (Szabo 2013). The very slightly lower than acceptable internal consistency of the EAI in the current sample (0.65) is another limitation that should be kept in mind when interpreting the findings. Finally, dichotomization using median split has been criticized in the literature, but relatively recent evidence (Iacobucci et al. 2015a, b) demonstrates that it is a reliable method to use.

\section{Conclusions}

The present study replicates recent findings in the field by demonstrating that obsessive passion is a predictor of REA scores, while harmonious passion has only a limited influence on REA scores. The present study also expands the previous findings by showing that REA, exercise intensity, and both obsessive passion and harmonious passion are higher among exercisers who work out in greater volumes. Furthermore, the study demonstrates a clear separation in the level of both obsessive passion and harmonious passion among individuals at REA and symptomatic and asymptomatic individuals. Consequently, increasing levels of REA appear to involve a growing hybrid of obsessive passion and harmonious passion that parallel the REA, further complicating the complex relationship between these concepts while raising new questions for future research.

Financial Support This study was supported by the Hungarian National Research, Development and Innovation Office (grant numbers: K111938, K109375).

\section{Compliance with Ethical Standards}

Ethical Clearance Ethical permission for the study was obtained from the Research Ethics Committee of the Faculty of Education and Psychology at ELTE Eötvös Loránd University.

Conflict of Interest The authors declare that they have no conflict of interest.

Open Access This article is distributed under the terms of the Creative Commons Attribution 4.0 International License (http://creativecommons.org/licenses/by/4.0/), which permits unrestricted use, distribution, and reproduction in any medium, provided you give appropriate credit to the original author(s) and the source, provide a link to the Creative Commons license, and indicate if changes were made.

\section{References}

American Psychiatric Association. (2013). Diagnostic and statistical manual of mental disorders (5th ed.). Arlington, VA: American Psychiatric Publishing.

Back, J. (2015). Profiles of exercise dependence - a person centred approach to study potential mechanisms. (Master's thesis). School of Health and Welfare: Halmstad University, Halmstad, Sweden. Retrieved from: http://www.diva-portal.org/smash/get/diva2:940447/FULLTEXT02 
Blaydon, M. J., \& Lindner, K. J. (2002). Eating disorders and exercise dependence in triathletes. Eating Disorders, 10(1), 49-60. https://doi.org/10.1080/106402602753573559

Borg, G. A. (1982). Psychophysical bases of perceived exertion. Medicine and Science in Sports and Exercise, 14(5), 377-381. https://doi.org/10.1249/00005768-198205000-00012

Costa, S., Hausenblas, H. A., Oliva, P., Cuzzocrea, F., \& Larcan, R. (2015). Perceived parental psychological control and exercise dependence symptoms in competitive athletes. International Journal of Mental Health and Addiction, 13(1), 59-72. https://doi.org/10.1007/s11469-014-9512-3

De La Vega, R., Parastatidou, I. S., Ruiz-Barquin, R., \& Szabo, A. (2016). Exercise addiction in athletes and leisure exercisers: the moderating role of passion. Journal of Behavioral Addictions, 5(2), 325-331. https://doi.org/10.1556/2006.5.2016.043

Demetrovics, Z., \& Kurimay, T. (2008). Testedzésfüggőség: a sportolás mint addikció (Exercise addiction: physical activity as addiction). Psychiatria Hungarica, 23(2), 129-141

Egorov, A. Y., \& Szabo, A. (2013). The exercise paradox: an interactional model for a clearer conceptualization of exercise addiction. Journal of Behavioral Addictions, 2(4), 199-208. https://doi.org/10.1556 /jba.2.2013.4.2

Faul, F., Erdfelder, E., Lang, A. G., \& Buchner, A. (2007). G* Power 3: a flexible statistical power analysis program for the social, behavioral, and biomedical sciences. Behavior Research Methods, 39(2), 175-191. https://doi.org/10.3758/BF03193146

Griffiths, M. D. (1997). Exercise addiction: a case study. Addiction Research, 5, 161-168. https://doi.org/10.3109 /16066359709005257

Griffiths, M. D., Urbán, R., Demetrovics, Z., Lichtenstein, M. B., de la Vega, R., Kun, B., et al. (2015). A crosscultural re-evaluation of the Exercise Addiction Inventory (EAI) in five countries. Sports Medicine-Open, 1(1), 1-7. https://doi.org/10.1186/s40798-014-0005-5

Hausenblas, H. A., Schreiber, K., \& Smoliga, J. M. (2017). Addiction to exercise. British Medical Journal, 357, j1745. https://doi.org/10.1136/bmj.j1745

Iacobucci, D., Posavac, S. S., Kardes, F. R., Schneider, M. J., \& Popovich, D. L. (2015a). Toward a more nuanced understanding of the statistical properties of a median split. Journal of Consumer Psychology, 25(4), 652-665. https://doi.org/10.1016/j.jcps.2014.12.002

Iacobucci, D., Posavac, S. S., Kardes, F. R., Schneider, M. J., \& Popovich, D. L. (2015b). The median split: robust, refined, and revived. Journal of Consumer Psychology, 25(4), 690-704. https://doi.org/10.1016/j. jcps.2015.06.014

Irwin, J. R., \& McClelland, G. H. (2003). Negative consequences of dichotomizing continuous predictor variables. Journal of Marketing Research, 40(3), 366-371. https://doi.org/10.1509/jmkr.40.3.366.19237

Marsh, H. W., Vallerand, R. J., Lafrenière, M.-A. K., Parker, P., Morin, A. J. S., Carbonneau, N., \& Paquet, Y. (2013). Passion: does one scale fit all? Construct validity of two-factor passion scale and psychometric invariance over different activities and languages. Psychological Assessment, 25(3), 796-809. https://oi. org/10.1037/a0032573

McNamara, J., \& McCabe, M. P. (2012). Striving for success or addiction? Exercise dependence among elite Australian athletes. Journal of Sports Sciences, 30(8), 755-766. https://doi.org/10.1080 /02640414.2012.667879

Monók, K., Berczik, K., Urbán, R., Szabo, A., Griffiths, M. D., Farkas, J., et al. (2012). Psychometric properties and concurrent validity of two exercise addiction measures: a population wide study. Psychology of Sport and Exercise, 13(6), 739-746. https://doi.org/10.1016/j.psychsport.2012.06.003

Orosz, G., Vallerand, R. J., Bőthe, B., Tóth-Király, I., \& Paskuj, B. (2016). On the correlates of passion for screen-based behaviors: The case of impulsivity and the problematic and non-problematic Facebook use and TV series watching. Personality and Individual Differences, 101, 167-176

Paradis, K. F., Cooke, L. M., Martin, L. J., \& Hall, C. R. (2013). Too much of a good thing? Examining the relationship between passion for exercise and exercise dependence. Psychology of Sport and Exercise, 14(4), 493-500. https://doi.org/10.1016/j.psychsport.2013.02.003

Parastatidou, I. S., Doganis, G., Theodorakis, Y., \& Vlachopoulos, S. P. (2012). Exercising with passion: initial validation of the passion scale in exercise. Measurement in Physical Education and Exercise Science, 16(2), 119-134. https://doi.org/10.1080/1091367X.2012.657561

Parastatidou, I. S., Doganis, G., Theodorakis, Y., \& Vlachopoulos, S. P. (2014). The mediating role of passion in the relationship of exercise motivational regulations with exercise dependence symptoms. International Journal of Mental Health and Addiction, 12(4), 406-419. https://doi.org/10.1007/s11469-013-9466-X

Philippe, F. L., Vallerand, R. J., \& Lavigne, G. L. (2009). Passion does make a difference in people's lives: a look at well-being in passionate and non-passionate individuals. Applied Psychology: Health and Well-Being, 1(1), 3-22. https://doi.org/10.1111/j.1758-0854.2008.01003.x

Qualtrics (2017). Survey research suite: research core ${ }^{\mathrm{TM}}$. Provo, Utah, USA. Available at: http://www.qualtrics. com. 
Schipfer, M., \& Stoll, O. (2015, July). Exercise-addiction/exercise commitment-model (EACOM). Paper presented at the 14th European Congress of Sport Psychology, Bern, Switzerland.

Schreiber, K., \& Hausenblas, H. (2017). Re: addiction to exercise: response - passion vs. pathology? British Medical Journal, 357, j1745 Retrieved from: http:/www.bmj.com/content/357/bmj.j1745/rr-7

Stenseng, F., Rise, J., \& Kraft, P. (2011). The dark side of leisure: obsessive passion and its covariates and outcomes. Leisure Studies, 30(1), 49-62. https://doi.org/10.1080/02614361003716982

Szabo, A. (2010). Addiction to exercise: a symptom or a disorder? New York: Nova Science.

Szabo, A. (2013). Acute psychological benefits of exercise: reconsideration of the placebo effect. Journal of Mental Health, 22(5), 449-455. https://doi.org/10.3109/09638237.2012.734657

Szabo, A., Griffiths, M. D., de la Vega, R., Mervó, B., \& Demetrovics, Z. (2015). Methodological and conceptual limitations in exercise addiction research. Yale Journal of Biology and Medicine, 88, 303-308.

Szabo, A., Griffiths, M. D., \& Demetrovics, Z. (2016). Exercise addiction. In V. R. Preedy (Ed.), Neuropathology of drug addictions and substance misuse volume 3: general processes and mechanisms, prescription medications, caffeine and areca, polydrug misuse, emerging addictions and non-drug addictions ( $\mathrm{p}$. 984.992). London: Academic Press.

Terry, A., Szabo, A., \& Griffiths, M. (2004). The exercise addiction inventory: a new brief screening tool. Addiction Research and Theory, 12, 489-499. https://doi.org/10.1080/16066350310001637363

Vallerand, R. J. (2010). On passion for life activities: the dualistic model of passion. In M. P. Zanna \& J. M. Olson (Eds.), Advances in experimental social psychology (pp. 97-133). San Diego, CA: Academic Press.

Vallerand, R. J., \& Miquelon, P. (2007). Passion for sport in athletes. In D. Lavallee \& S. Jowett (Eds.), Social psychology in sport (pp. 249-262). Champaign, IL: Human Kinetics.

Vallerand, R. J., Blanchard, C., Mageau, G. A., Koestner, R., Ratelle, C., Leonard, M., Gagne, M., \& Marsolais, J. (2003). Les passions de l'ame: on obsessive and harmonious passion. Journal of Personality and Social Psychology, 85(4), 756-767. https://doi.org/10.1037/0022-3514.85.4.756

Vallerand, R. J., Rousseau, F. L., Grouzet, F. M. E., Dumais, A., Grenier, S., \& Blanchard, C. M. (2006). Passion in sport: a look at determinants and affective experiences. Journal of Sport and Exercise Psychology, 28(4), 454 478. https://doi.org/10.1123/jsep.28.4.454

Vallerand, R. J., Salvy, S. J., Mageau, G. A., Elliot, A. J., Denis, P., Grouzet, F. M. E., \& Blanchard, C. (2007). On the role of passion in performance. Journal of Personality, 75(3), 505-534. https://doi.org/10.1111 /j.1467-6494.2007.00447.x

Vallerand, R. J., Mageau, G. A., Elliot, A. J., Dumais, A., Demers, M. A., \& Rousseau, F. (2008). Passion and performance attainment in sport. Psychology of Sport and Exercise, 9(3), 373-392. https://doi.org/10.1016/j. psychsport.2007.05.003 